\title{
TO ALIGN OR NOT TO ALIGN?
}

\section{Philip J Radford, Foundation Dentist}

\section{Introduction}

Adverts for teeth straightening using clear braces are everywhere on social media at the moment. In this article, we take a closer look behind the glossy 'before' and 'after' photographs at what this phenomenon means for dental students.

Clear orthodontic aligners have been used to straighten teeth for many years. ${ }^{1}$ As we all know, the availability of smart phone technology has made taking and sharing 'selfies' part of everyday life. It is no surprise that young people and adults are more conscious about the appearance of their teeth and are seeking 'invisible' treatment to improve their dental appearance. ${ }^{2}$ Patients undergoing this type of treatment in the UK pay for it on a private basis and wear a series of custom-made aligners, changing them every few weeks. As part of the treatment, their teeth may also be modified by removing small amounts of interproximal enamel.

\section{What are some of the advantages} of using clear aligners to straighten teeth compared to traditional fixed appliances such as 'traintracks'? Aside from the obvious advantage that these braces are virtually invisible, they are also more hygienic and less likely to cause caries as they can be regularly removed for cleaning. Some research also shows that these braces may be less painful. ${ }^{3}$ Currently, we do not know if these types of braces are more effective at straightening teeth due to a lack of high-quality evidence. ${ }^{4}$

\section{What might be some of the disadvantages of using clear aligners?}

Certain tooth movements and managing treatment where extraction of teeth is necessary has been reported to be challenging when using clear aligners. ${ }^{5}$ Dentists often use custom software to give patients a visual computer model of how a completed care plan might change a patient's appearance. ${ }^{6}$ It has been commented that dentists should be careful to ensure that these tooth movements are in fact possible before discussing the possible aesthetic outcomes with patients. ${ }^{6}$ The ultimate responsibility for the treatment and its result lies with the dentist and not dental technicians based at a remote site who have perhaps planned all of the virtual tooth movements on the computer software.

\section{'As dental students, an awareness of this type of treatment is vital'}

Can I treat patients with clear aligners when I graduate and am working as a general dental practitioner (GDP)?

Many GDPs treat patients using clear aligner systems such as 'Invisalign'. The GDC standards state that we must obtain valid consent for treatment and maintain, develop and work within our professional knowledge and skills. ${ }^{7}$ It is therefore important to:

1. Have enough orthodontic knowledge about the risks, benefits and capabilities of the various appliances and options available for straightening teeth in order to obtain truly valid consent from a patient. Dentists who have undertaken further training and have used different methods to straighten teeth are best placed to do this. Remember, 'if you only have a hammer, everything looks like a nail!'

2. Be able to confidently and accurately assess the patient in the first place in order to make good clinical decisions and to manage patient expectations.
What should we tell patients about the online 'DIY ortho' adverts that they may ask us about?

Direct-to-consumer orthodontics or 'DIY ortho', where patients can sign up to take their own impressions at home and receive clear aligners for treatment without interacting in person with a qualified dentist, are being heavily advertised online at competitive prices. The British Orthodontic Society (BOS) and Oral Health Foundation, have recently announced the launch of a campaign to advise patients in all circumstances to visit a trained clinician ensuring that they have the various options open to them explained so they can make an informed decision. ${ }^{8}$ Companies providing such treatment risk treating patients simply as consumers and their attractive adverts do not appear to detail the potential risks of orthodontic treatment e.g. pain, caries, periodontal disease, and root and alveolar bone resorption.

In conclusion, clear aligners are rising in popularity and are heavily advertised on social media platforms. ${ }^{9}$ As dental students, an awareness of this type of treatment is vital in order to be able to answer the inevitable questions from patients. This type of dental treatment can have important life changing benefits for patients but needs to be provided ethically and after informed consent.

\section{References}

1. Vlaskalic V, Boyd R. Orthodontic treatment of a mildly crowded malocclusion using the Invisalign System. Aust Orthod J 2001; 17: 41-46.

2. The number of adults seeking orthodontic treatment in the UK continues to rise. Br Dent J 2018; 224: 847.

3. Miller K B. A comparison of treatment impacts between Invisalign aligner and fixed appliance therapy during the first week of treatment. $A m \mathrm{~J}$ Orthod Dentofacial Orthop 2007; 131: 302.

4. Orthodontic Aligner Treatment. Kevin O’Brien's Orthodontic Blog. Available at: https:// kevinobrienorthoblog.com/orthodontic-alignertreatment/ (Accessed July 2020).

5. Phan X, Ling P H. Clinical limitations of Invisalign. J Can Dent Assoc 2007; 73: 263-266.

6. Noar J, Sharma S, Roberts-Harry D et al. A discerning approach to simple aesthetic orthodontics. Br Dent J 2015; 218: 157-166.

7. GDC Standards for the dental team. Available at https://www.gdc-uk.org/professionals/standards/ team (Accessed June 2020).

8. Campaign to alert patients to the dangers of 'DIY Ortho' announced at BOC 2019. British Society of Orthodontists. Available at: https://www.bos.org.uk/ News-and-Events/News (Accessed June 2020).

9. Westgarth, D. Social media: A picture perfect storm? BDJ In Pract 2019; 32: 4

Philip J Radford 